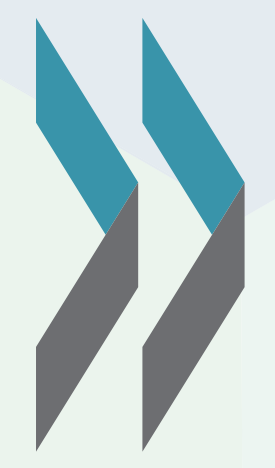

\title{
What kinds of activities are common among teenagers who work well with others?
}

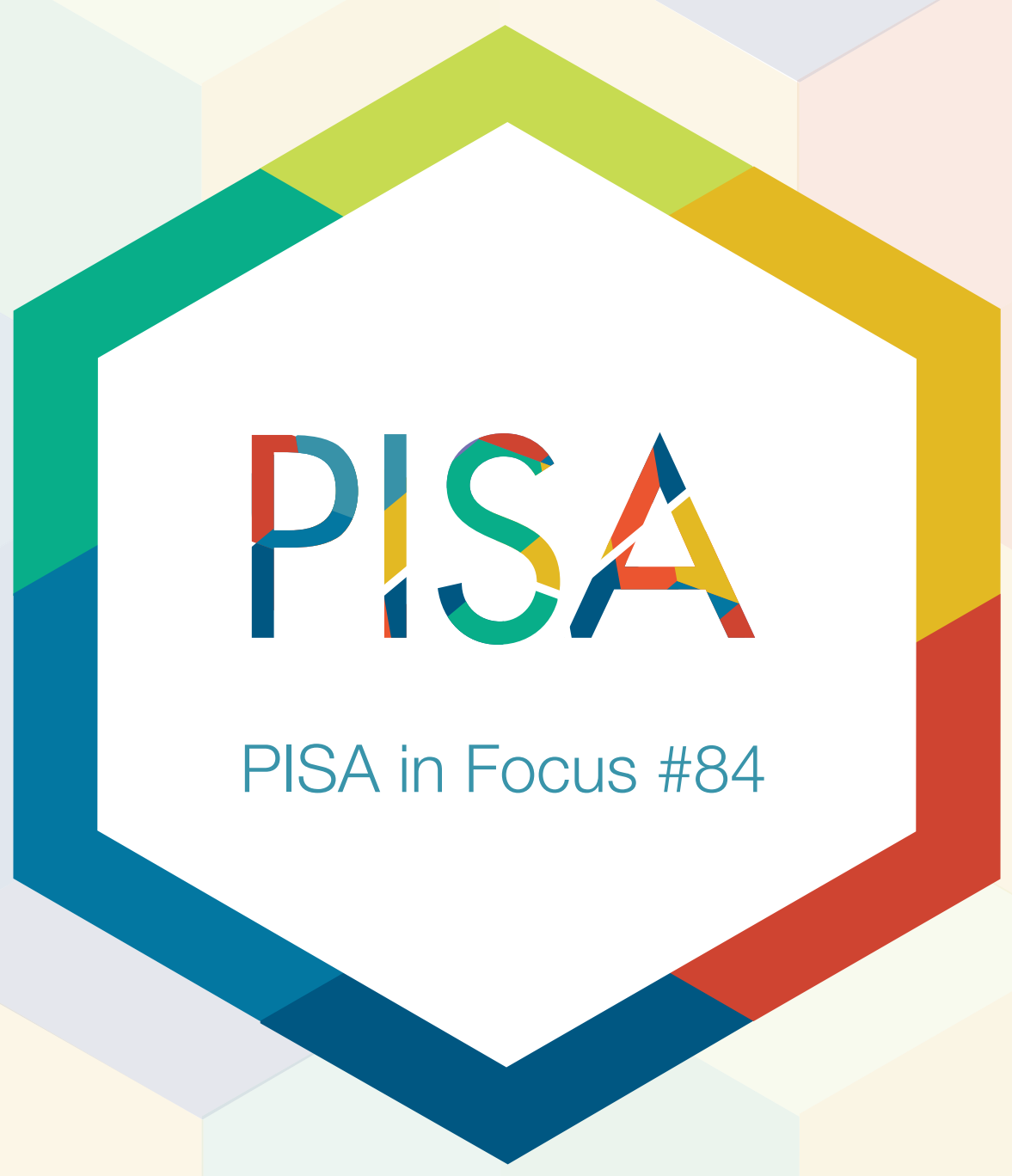




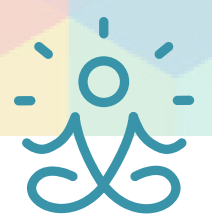

\section{What kinds of activities are common among teenagers who work well with others?}

- Students who engage in more moderate physical activity are better at collaborating with others to solve problems and have more positive attitudes towards their team members.

- Students who access the Internet, chat or social networks outside of school collaborate better than students who do not engage in these activities, while students who play video games outside of school collaborate worse than students who do not play video games.

- Students who work in the household or take care of other family members value teamwork more and have better attitudes towards their team members than other students, as do students who regularly meet friends or talk to friends on the phone.

Schools are not just four walls inside of which students learn how to read, write and think. Schools provide a venue where young people meet each other, and where they develop relationships and friendships that may last for decades. At school, students socialise and hone the interpersonal skills that are required to function effectively in the workplace and in society at large.

Employers value such skills more now than ever before: wages have risen more for jobs that demand a high level of social skills than for jobs that require only a low level of social skills. But until now, there was no measure of students' ability to work together that was consistent across countries. PISA changed that when it introduced its collaborative problem-solving assessment in 2015, which, more specifically, measured students' ability to work together to solve problems and achieve goals.

PISA finds that students who perform well in science, reading and mathematics also tend to perform well in the collaborative problem-solving assessment. By accounting for performance in these three subjects, PISA is able to isolate the part of the performance in the collaborative problem-solving assessment that is specific to collaboration skills. That part is known as the relative performance.

Students in Australia, Japan, Korea, New Zealand, Singapore and the United States show the highest relative performance in collaborative problem solving, on average, and are therefore among the world's best in working together with others. But what distinguishes between students who collaborate well with others and those who do not? Are the ability to collaborate and attitudes towards collaboration related to certain activities?

\section{Physically active students score higher in collaborative problem solving.}

There is a positive relationship between the number of days per week that students engage in moderate physical activity - activities such as walking, climbing stairs or riding a bicycle for at least 60 minutes a day and performance in collaborative problem solving. Boys who engaged in at least five days of moderate physical activity during the week prior to the PISA assessment scored higher in collaborative problem solving than boys who engaged in fewer than five days of moderate physical activity. Among girls, higher scores in collaborative problem solving were observed after only two days of moderate physical activity.

However, the collaboration-specific skills of such students do not vary with the frequency of moderate physical activity, because student performance in the science, reading and mathematics assessments also improves with the frequency of moderate physical activity. Hence, while students who are more physically active are 


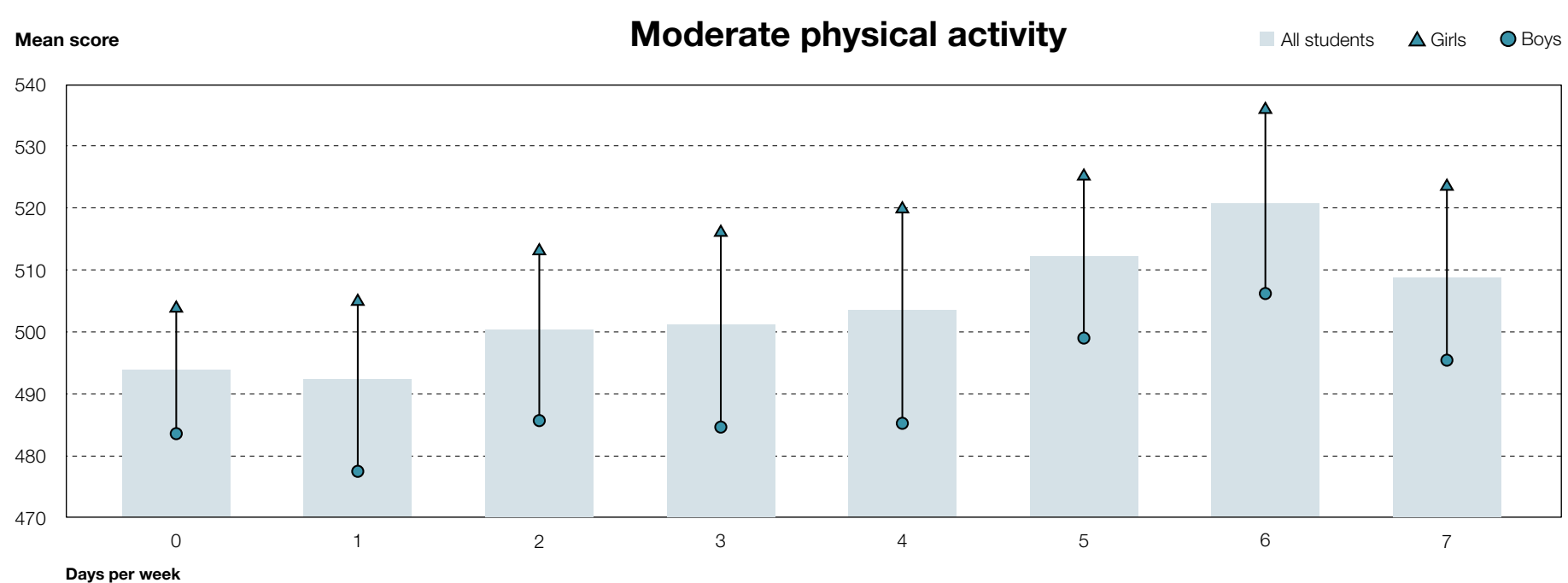

Notes: The average score across OECD countries was standardised at 500 score points with a standard deviation of 100 score points.

Moderate physical activity includes walking, climbing stairs or riding a bicycle to school for at least 60 minutes per day.

Source: OECD, PISA 2015 Database, Table V.6.1a.

better at solving problems collaboratively (as measured by the assessment), they are not necessarily better at the act of collaboration itself.

A greater weekly engagement in moderate physical activity is also linked to more positive attitudes towards one's team members. There is a positive, although weaker, link with attitudes towards teamwork.

\section{Some other out-of-school activities are positively related to students' ability to work in teams and to their confidence in this ability.}

PISA 2015 asked students whether they participated in a variety of activities before or after school on the most recent school day prior to sitting the PISA assessment. Several of these activities might have a social - or perhaps antisocial - component to them: using the Internet/chat/social networks; playing video games; meeting friends or talking to friends on the phone; and working in the household or taking care of family members.

On average across OECD countries, a significant and negative association is observed between playing video games and the ability to collaborate. Students who played video games outside of school scored four points lower in relative performance than students who did not play video games, after accounting for gender and students' and schools' socio-economic profiles.

By contrast, accessing the Internet, chat or social networks outside of school is associated with higher relative performance in collaborative problem solving. On average across OECD countries, students who routinely accessed digital media scored a significant six points higher than students who did not do so. 


\section{Activities before and after school, and performance in collaborative problem solving}

Difference in collaborative problem-solving performance between students who reported that they had engaged in these activities before or after school and those who reported that they had not, after accounting for performance in science, reading and mathematics, gender, and students' and schools' socio-economic status, OECD average

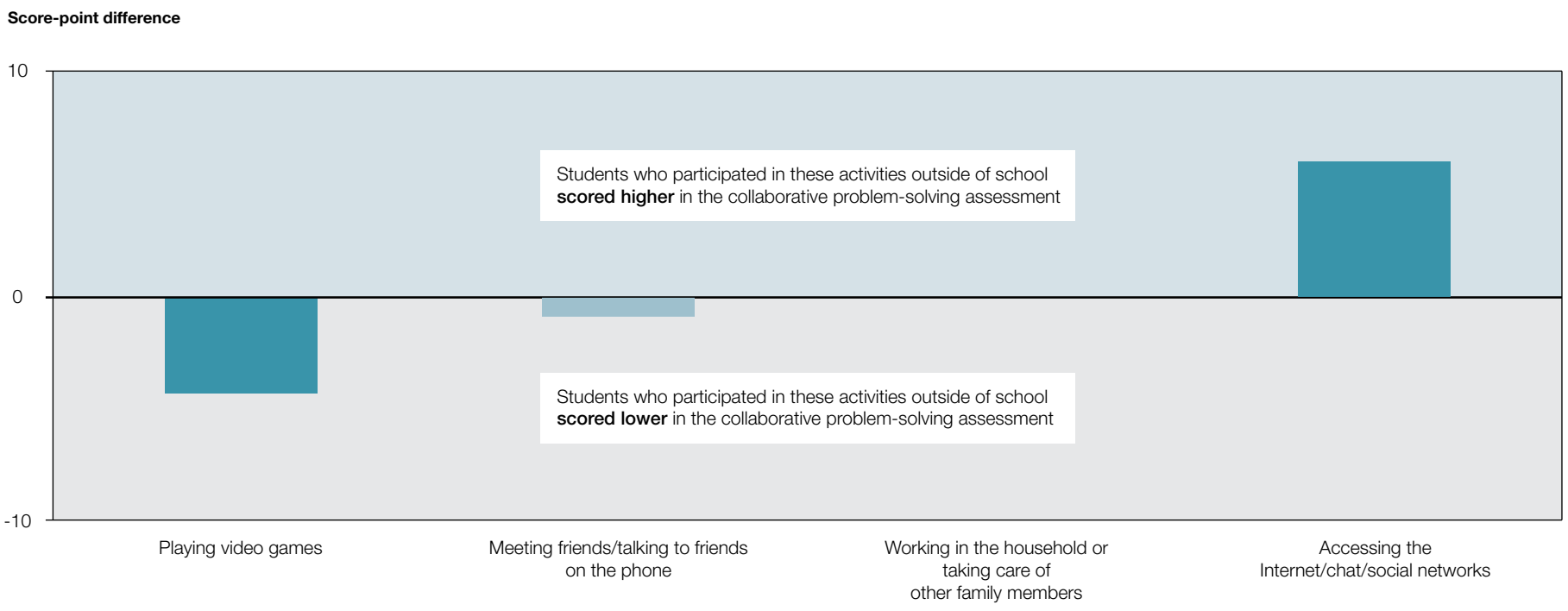

Notes: Score-point differences that are statistically significant are shown in a darker tone.

Students were asked whether they had engaged in these activities before or after school on the most recent school day prior to the PISA assessment. Activities are ranked in ascending order of the score-point difference in collaborative problem solving, after accounting for performance in science, reading and mathematics, gender, and students' and schools' socio-economic profile.

Source: OECD, PISA 2015 Database, Tables V.6.7a-d.

There is no significant difference in relative performance observed between students who met friends or talked to friends on the phone compared to those who did not; or between students who worked in the household or took care of family members compared to those who did not.

However, participation in each of the four out-of-school activities described above is associated with a significant change in students' attitudes towards teamwork and collaboration. Students who met friends or talked to friends on the phone outside of school reported more positive attitudes towards their team members and enjoyed teamwork more than students who did not meet or talk with friends on the phone, after accounting for gender and students' and schools' socio-economic profile. This difference was also significant in 54 out of 57 countries for which data are available.

Students who worked in the household or took care of family members also reported more positive attitudes towards team members and enjoyed teamwork more than students who did not engage in these activities. A significant difference was observed in this regard in almost every education system that conducted the collaborative problem-solving assessment.

Students who accessed the Internet, chat or social networks outside of school were significantly more likely to report that they enjoy teamwork than students who did not, but they reported slightly poorer attitudes towards team members. The same was observed among students who played video games: they enjoyed teamwork slightly more, but were not as positive about their team members. 


\section{Activities before and after school, and attitudes towards collaboration}

Difference in attitudes towards collaboration between students who reported that they had engaged in these activities before or after school and those who reported that they had not, after accounting for gender and students' and schools' socio-economic status, OECD average

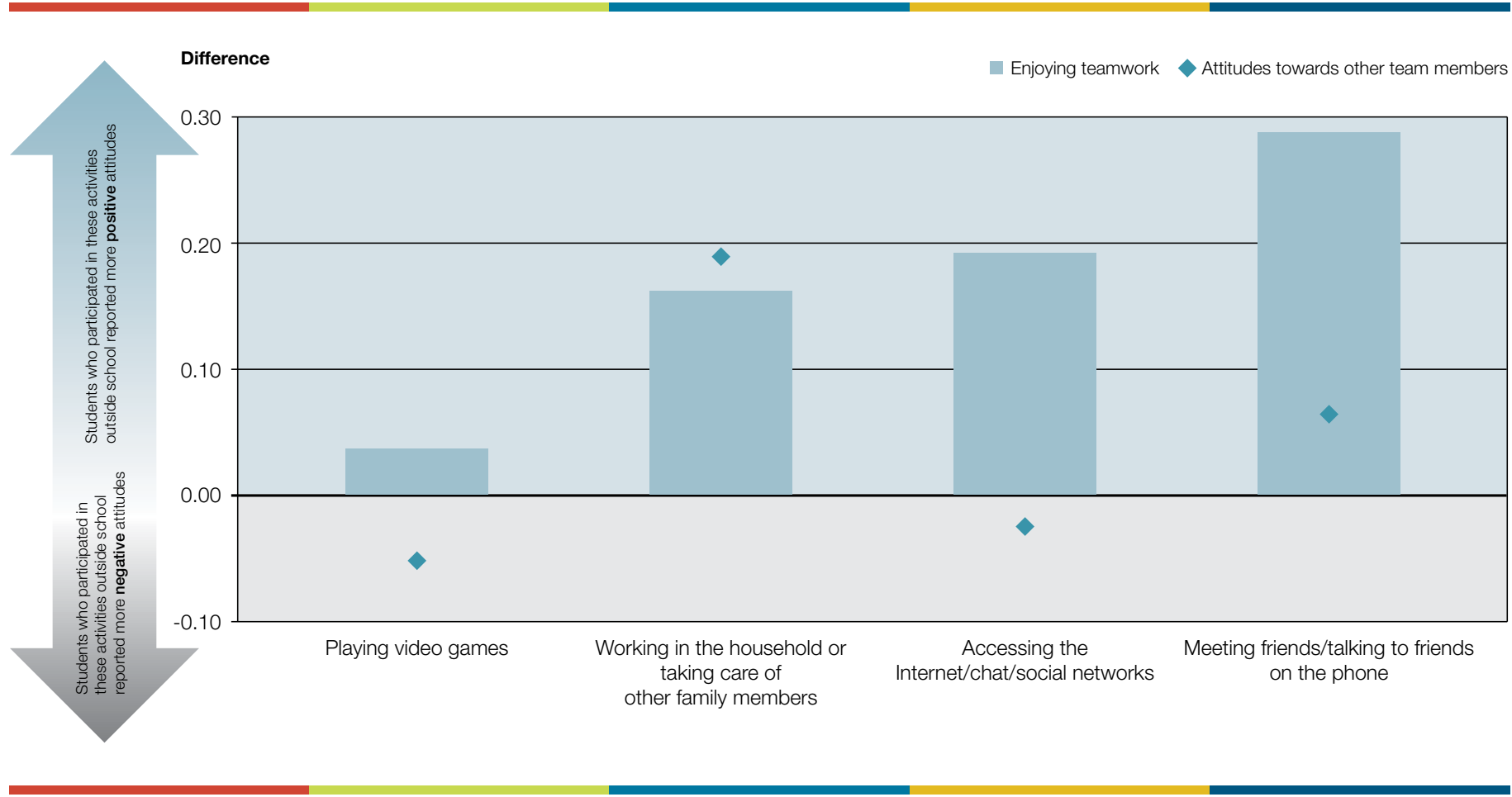

Notes: All differences are statistically significant.

Students were asked whether they had engaged in these activities before or after school on the most recent school day prior to the PISA assessment. Activities are ranked in ascending order of the difference in the index of valuing (enjoying) teamwork, after accounting for gender and students' and schools' socio-economic profile.

Source: OECD, PISA 2015 Database, Tables V.6.8a-d.

\section{The bottom line}

A variety of activities are correlated with how well students collaborate with others and how they view collaboration. Parents, schools and communities can encourage teenagers to engage in these activities, whether by being more physically active, helping out more around the household, or spending less time playing video games. This should be combined with school activities that teach, exercise and develop students' collaboration skills, skills that are increasingly valued in the workforce and in society in general. 


\section{For more information}

Contact: Jeffrey Mo (Jeffrey.Mo@oecd.org)

See: OECD (2017), PISA 2015 Results (Volume V): Collaborative Problem Solving, OECD Publishing, Paris, http://dx.doi.org/10.1787/9789264285521-en.

Coming next month: In which countries do the best teachers teach in the most difficult schools?

This paper is published under the responsibility of the Secretary-General of the OECD. The opinions expressed and the arguments employed herein do not necessarily reflect the official views of OECD member countries.

This document, as well as any data and map included herein, are without prejudice to the status of or sovereignty over any territory, to the delimitation of international frontiers and boundaries and to the name of any territory, city or area.

This work is available under the Creative Commons Attribution-NonCommercial-ShareAlike 3.0 IGO (CC BY-NC-SA 3.0 IGO). For specific information regarding the scope and terms of the licence as well as possible commercial use of this work or the use of PISA data please consult Terms and Conditions on www.oecd.org. 